\title{
HEMORRAGIA INTRACEREBRAL TEMPRANA COMO PRESENTACIÓN ATÍPICA DE ENCEFALITIS POR HERPES VIRUS SIMPLE TIPO 1
}

\author{
Carlos A. Cueto-Fuentes (i) 1,2,a \\ 1 Instituto Nacional de Salud del Niño, Lima, Perú. \\ 2 Facultad de Medicina, Universidad Peruana Cayetano Heredia, Lima, Perú. \\ a Médico Pediatra, Médico Auditor.
}

\section{RESUMEN}

La encefalitis por herpes virus simple es la causa más común de encefalitis esporádica letal en el mundo. Una complicación poco usual es la hemorragia intracerebral. Se describe el caso de un preescolar de tres años que ingresa con cuadro clínico de encefalitis aguda, con hallazgos de hemorragia intracerebral temprana en región occipital y estudio en líquido cefalorraquídeo positivo para herpes virus tipo 1, que recibe tratamiento con aciclovir; sin embargo, cursa con evolución tórpida, incremento de hemorragias intracerebrales y desenlace fatal.

Palabras claves: Herpes Virus Humano Tipo 1; Encefalitis; Hemorragia Intracerebral Temprana (fuente: DeCS BIREME).

\section{EARLY INTRACEREBRAL HEMORRHAGE AS AN ATYPICAL PRESENTATION OF HERPES SIMPLEX-1 VIRUS ENCEPHALITIS}

\begin{abstract}
Herpes simplex encephalitis is the most common cause of sporadic lethal encephalitis in the world. Intracerebral hemorrhage is an uncommon complication. The case of a 3-year-old preschooler who was admitted with acute encephalitis clinical picture is described. The patient presents findings of early intracerebral hemorrhage in the occipital region and a positive cerebrospinal fluid study for herpes virus type 1, which is treated with acyclovir; however, it presents a torpid evolution, increased intracerebral hemorrhages and fatal outcome.
\end{abstract}

Keywords: Herpes Simplex virus; type 1; encephalitis; early intracerebral hemorrhage (source: MeSH NLM).

\section{INTRODUCCIÓN}

Citar como: Cueto-Fuentes CA. Hemorragia intracerebral temprana como presentación atípica de encefalitis por herpes virus simple tipo 1. Rev Peru Med Exp Salud Publica. 2020;37(1):15559. Doi: https://doi.org/10.17843/ rpmesp.2020.371.4384

Correspondencia: Carlos A. CuetoFuentes; Av. 28 de Julio 154 dpto. 306, Jesús María. Lima; carlos.cueto@upch.pe

Recibido: $20 / 03 / 2019$

Aprobado: 05/02/2020

En línea: 23/03/2020
La encefalitis por herpes virus simple (HSV) es la causa más común de encefalitis esporádica letal a nivel mundial; afecta, aproximadamente, 1 de 250000 a 1 de 1000000 de personas por año $^{(1,2)}$. Cerca del $90 \%$ de casos en adultos y niños se da por HSV-1, mientras que el HSV-2 predomina en neonatos ${ }^{(2,3)}$.

Una presentación atípica es la hemorragia intracerebral (HIC), presente en la segunda semana de enfermedad, afecta los lóbulos temporales, la ínsula y la región orbital de los lóbulos frontales; sin embargo, en niños, la afectación extra temporal tiene mayor incidencia ${ }^{(4-8)}$.

Se reporta el caso de un niño con encefalitis por HSV-1 que debuta con HIC, con evolución tórpida y desenlace fatal.

\section{REPORTE DE CASO}

Un paciente varón de tres años con diez meses de edad, procedente de Comas, en Lima, sin antecedentes previos, ingresó por emergencia con dos días de enfermedad, caracterizada por fiebre, cefalea y vómitos no explosivos. Ocho horas previas al ingreso, presentó convulsión 
focalizada con desviación de la mirada por tres minutos de duración sin pérdida de conciencia. Cinco horas después, en el centro de salud, presentó fiebre y convulsión tónico-clónica generalizada con desviación de la mirada a la derecha de diez minutos de duración que cedió con benzodiacepinas. Fue referido al Instituto Nacional de Salud del Niño.

$\mathrm{Al}$ ingreso, se observó un paciente subfebril, irritable, con cefalea intermitente, Glasgow 15 y sin signos meníngeos; se plantea el diagnóstico de convulsión febril compleja y posibilidad diagnóstica de meningoencefalitis. Los resultados de exámenes auxiliares se presentan en la Tabla 1.

En las siguientes horas, sigue febril, irritable, con cefalea y marcha atáxica. El padre no autorizó el estudio del líquido cefalorraquídeo (LCR). La tomografía espiral multicorte (TEM) cerebral, sin contraste, muestra lesión hiperdensa compatible con hemorragia en región occipital izquierda (Figura 1). El neurocirujano indica tratamiento con Manitol y Fenitoína.

A las 36 horas, la evaluación neuropediátrica lo encuentra despierto, irritable, Glasgow: ocular con cuatro puntos, verbal con cuatro y motora con seis, sin signos meníngeos, signo de Babinski negativo, reflejos osteotendinosos (ROT) conservados y pupilas isocóricas. El estudio del LCR mostró leucorraquia con predominio linfocitario (Tabla 2). Se indicó ceftriaxona, aciclovir y dexametasona vía endovenosa (EV).

El tercer día, sigue con fiebre, cefalea, rigidez de nuca, signo de Kerning positivo y visión borrosa. El examen del fondo de ojo no mostró alteraciones. La angiotomografía cerebral evidencia lesión hemorrágica en región occipital con discreto edema periférico y sin malformaciones vasculares. Al cuarto día, la evaluación fue estacionaria. Reacción en cadena de la polimerasa (PCR) para HSV-1 en LCR fue

Tabla 1. Exámenes auxiliares al ingreso al Instituto Nacional de Salud del Niño

\begin{tabular}{lcc}
\hline Variable & Rango referencial & Resultado \\
\hline Hemoglobina (g/dL) & $11,5-12,5$ & 10,2 \\
Hematocrito (\%) & $34-37$ & 31 \\
Plaquetas $\left(10^{3}\right.$ por $\left.\mathrm{mm}^{3}\right)$ & $150-450$ & 268 \\
Leucocitos $\left(10^{3}\right.$ por $\left.\mathrm{mm}^{3}\right)$ & $6-17$ & 9,76 \\
Eosinófilos (\%) & 0 & 0 \\
Abastonados (\%) & 0 & 0 \\
Segmentados (\%) & 33 & 70 \\
Linfocitos (\%) & 59 & 28 \\
Monocitos (\%) & 5 & 2 \\
Tiempo de protrombina (s.) & $12,1-14,5$ & 12,9 \\
TTPA (s.) & $29,6-39,7$ & 32,9 \\
Fibrinógeno (mg/dL) & $198-481$ & 282 \\
PCR (mg/dL) & $0,0-0,5$ & 0,09 \\
Glucosa (mg/dL) & $70-99$ & 90 \\
Urea (mg/dl) & 36 & 23 \\
Creatinina (mg/dL) & $0,3-0,7$ & 0,43 \\
VIH & & No reactivo \\
Ag. Sup. Hepatitis B & & No reactivo \\
Anticuerpo hepatitis C & & No reactivo \\
\hline
\end{tabular}

TTPA: Tiempo de tromboplastina parcial activado. Ag.Sup.: Antígeno de superficie.
Tabla 2. Estudio de líquido cefalorraquídeo al ingreso al Instituto Nacional de Salud del Niño

\begin{tabular}{lcc}
\hline Variable & Rango referencial & Resultado \\
\hline Aspecto & Cristal de roca & Turbio \\
Leucocitos $\left(\right.$ por $\left.\mathrm{mm}^{3}\right)$ & $0-7$ & 36 \\
Diferencial (\%) & & \\
Polimorfonuclear & $0-35$ & 16 \\
Mononuclear & $65-100$ & 84 \\
Hematíes & 0 & $10-12$ \\
Glucosa (mg/dl) & $40-80$ & 50,1 \\
Proteínas $(\mathrm{mg} / \mathrm{dl})$ & $5-40$ & 51,4 \\
Tinción $\mathrm{Gram}$ & & Negativo \\
\hline
\end{tabular}

positivo, confirmando el diagnóstico de encefalitis por HSV1. En el quinto día presenta dos episodios de convulsión tónico-clónica generalizada con desviación de la mirada de 30 segundos de duración. La resonancia magnética nuclear (RMN) cerebral mostró compromiso de parte posterior del hemisferio cerebral izquierdo, aumento de volumen y edema, sangrado en cara inferior de lóbulo temporal y polo occipital izquierdo (Figura 2). Tras ello, presentó convulsiones con paro cardiorrespiratorio, recibió reanimación cardiopulmonar y quedó con soporte ventilatorio.

En la nueva TEM cerebral sin contraste, se evidenció hemorragia parieto-occipital izquierda que comprometió hipocampo y córtex estriado, con marcado edema vasogénico circulante desplazando línea media hacia la derecha e incremento de sangrado respecto a estudios previos (Figura 3). El servicio de neurocirugía la describió como HIC, edema y tronco cerebral enclavado.

El paciente tuvo evolución tórpida, pupilas arrefléxicas, midriáticas, reflejo del dolor negativo, ROT y reflejo nauseoso negativos, sin patrón ventilatorio propio. Neuropediatría planteó coma profundo arrefléxico y encefalitis herpética hemorrágica.

En los siguientes días, el paciente cursó con deterioro sistémico, trastornos hidroeléctricos, neumotórax a tensión, sepsis, oliguria y falla multiorgánica. Falleció a los 20 días de su ingreso.

\section{DISCUSIÓN}

La encefalitis por HSV presenta una distribución bimodal con un tercio de casos entre los seis meses y los veinte años (pico de seis meses a tres años) y casi la mitad en mayores de 50 años $^{(2,5)}$. Pasada la etapa neonatal, el HSV-1 es más frecuente en niños y adultos $(90 \% \text { de casos })^{(2,3.9)}$. En Perú, un estudio prospectivo multicéntrico encontró $84 \%$ de encefalitis por HSV- ${ }^{(10)}$.

El HSV-1 ingresa vía mucosa o piel dañada, con un gran porcentaje de primoinfección asintomática ${ }^{(4)}$. Respecto a la patogénesis de la encefalitis por HSV en niños, cerca del $30 \%$ es por primoinfección y $70 \%$ por reactivación. Las potenciales vías de ingreso del HSV-1 al sistema nervioso central (SNC) incluyen: a) infección primaria orofaríngea con invasión vía tractos del nervio olfatorio y trigémino, 


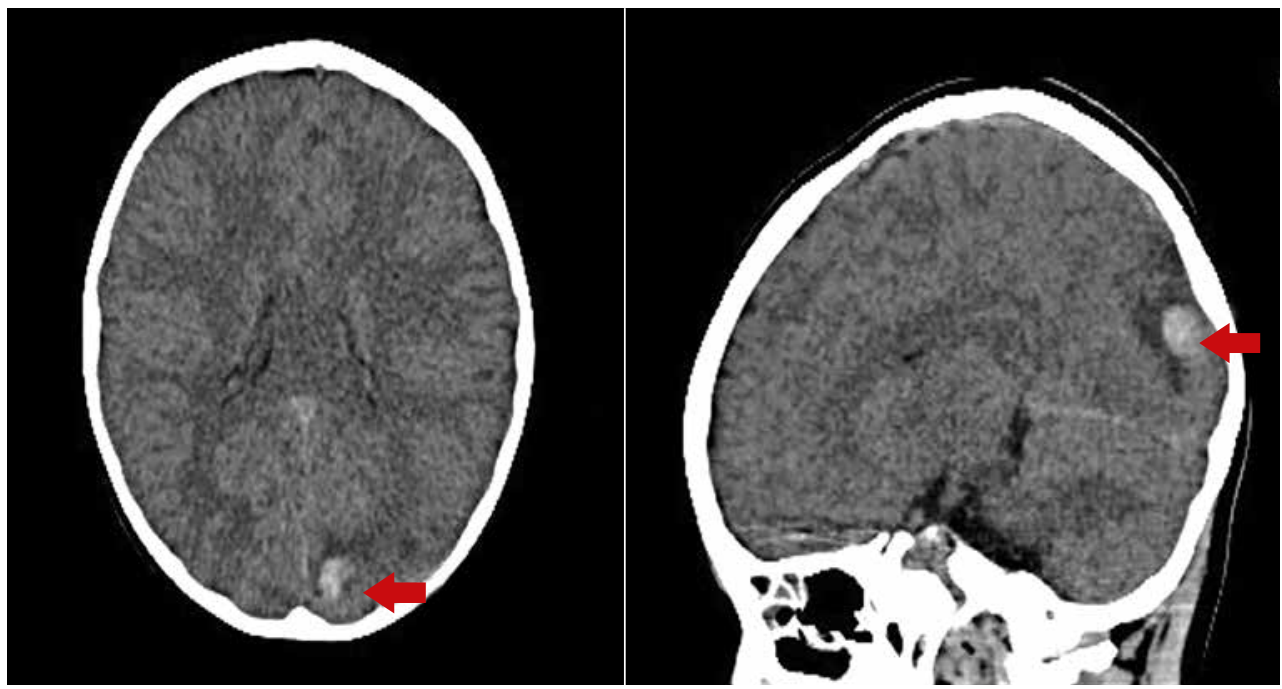

Figura 1. Tomografía computarizada de cerebro sin contraste. Corte axial y sagital. Área hiperdensa de forma anular a nivel de región occipital izquierda de $11 \times 8 \mathrm{~mm}$ aproximadamente, cuya densidad oscila entre 43 y $48 \mathrm{~mm} \mathrm{UH}$ asociado a edema periférico.

b) propagación hematógena, c) reactivación viral periférica con propagación axonal e d) infección del SNC sin infección periférica definida ${ }^{(2)}$.

La clínica se manifiesta por un cuadro agudo de cefalea, fiebre, alteración de conciencia, cambios de conducta, signos neurológicos focales (hemiparesia, ataxia, alteración de pares craneales), meníngeos y convulsiones en $50 \%$ de casos. El paciente empezó con fiebre y cefalea, considerados como síntomas precoces y constantes en varios estudios ${ }^{(4,5,7,9,10)}$; agregándose posteriormente convulsión, ataxia, irritabilidad y signos meníngeos. Estas manifestaciones asociadas a la TEM cerebral con lesión hemorrágica y LCR con leucorraquia (predominio linfocitario), fueron indicativos de encefalitis viral a descartar HSV, por lo cual se instauró terapia con aciclovir a $20 \mathrm{mg} / \mathrm{kg}$ c/8h EV. Los pacientes tratados con aciclovir dentro del segundo día de admisión tienen mejor pronóstico ${ }^{(7)}$, pues disminuye la mortalidad del $70 \%$ en no tratados a un $20-30 \%$. La dosis estándar de aciclovir es $10 \mathrm{mg} / \mathrm{kg} \mathrm{c} / 8 \mathrm{~h} \mathrm{EV;} \mathrm{sin} \mathrm{embar-}$ go, algunos recomiendan dosis altas en pediatría $(20 \mathrm{mg} / \mathrm{kg} \mathrm{c} / 8 \mathrm{~h})$ por aproximadamente 21 días ${ }^{(4,5)}$

El LCR es anormal en más del 95\% de casos, caracterizado por leucorraquia (10-200 células $/ \mathrm{mm}^{3}$ ), predominio linfocitario, algunos hematíes, que reflejan daño hemorrágico parenquimal (hallazgos encontrados en el caso); asimismo, un incremento moderado de proteínas en $85 \%$ de casos e hipoglucorraquia en menos del $5 \%{ }^{(4)}$. El diagnóstico se confirma con PCR (+) para HSV en LCR, considerado el «gold standard», (sensibilidad 96\% y especificidad 99\%). En pacientes pediátricos, existe un mayor porcentaje de falsos negativos principalmente en los primeros días de enfermedad, con lo que la sensibilidad baja a $70-75 \%{ }^{(5)}$.

Los estudios de imágenes permiten ver lesiones cerebrales clásicas del HSV (hemorrágicas y necróticas). La TEM tiene baja sensibilidad en detectar cambios o lesiones parenquimales durante los primeros días de enfermedad con áreas hipodensas en región temporal y ocasionalmente hiperdensas que representan zonas de hemorragias ${ }^{(7,9)}$. En el presente caso, la TEM, al ingreso, muestra lesión focal hiperdensa en la región occipital con edema periférico, compatible con HIC. La RMN es el estudio de elección para detección pre$\mathrm{COZ}$ de lesiones por HSV por su mayor sensibilidad, ya que más del $90 \%$ de casos con PCR (+) para encefalitis herpética tienen $\mathrm{RMN}$ anormal ${ }^{(7)}$. Las lesiones típicas son áreas de necrosis y hemorragia que envuelven región media del lóbulo temporal (amígdala, hipocampo, uncus), estructuras inferiores del lóbulo frontal (corteza frontal orbital y giro cingular) y corteza insular ${ }^{(2)}$. Sin embargo, el paciente evolucionó con lesiones extensas a nivel parietal, temporal, occipital, hipocampo y córtex estriado, reafirmando estudios previos que mencionan que la afectación extra temporal (zona occipital, parietal, cerebelo, opercular y talámica) es frecuente en niños ${ }^{(2,5,7,8,11)}$. De Tiège et al., describen afectación extra temporal en el $40 \%$ de la población pediátrica frente a un 9-15\% de adultos con $\mathrm{HSV}^{(5)}$.

La HIC por encefalitis HSV es rara y su mecanismo poco claro. Se postula que produce una vasculitis o vasculopatía necrótica que, asociada al incremento de la presión intracraneal, ocasiona la ruptura de vasos pequeños y, en consecuencia, produce sangrado cerebral ${ }^{(1,12-14)}$. Otra teoría es que la respuesta inflamatoria inmune daña el tejido cerebral y lo hace más propenso al sangrado espontáneo ${ }^{(12)}$. El paciente debutó con HIC a las horas del ingreso, lo cual es raro, ya que el sangrado se presenta generalmente en la segunda semana; como lo describe Bewersdorf et al., en $33 \%$ de sus casos ${ }^{(1)}$. Ante esto, algunos sugieren que el inicio precoz del tratamiento no disminuye el riesgo de sangrado ${ }^{(12,14-16)}$. Una revisión de Ro- 


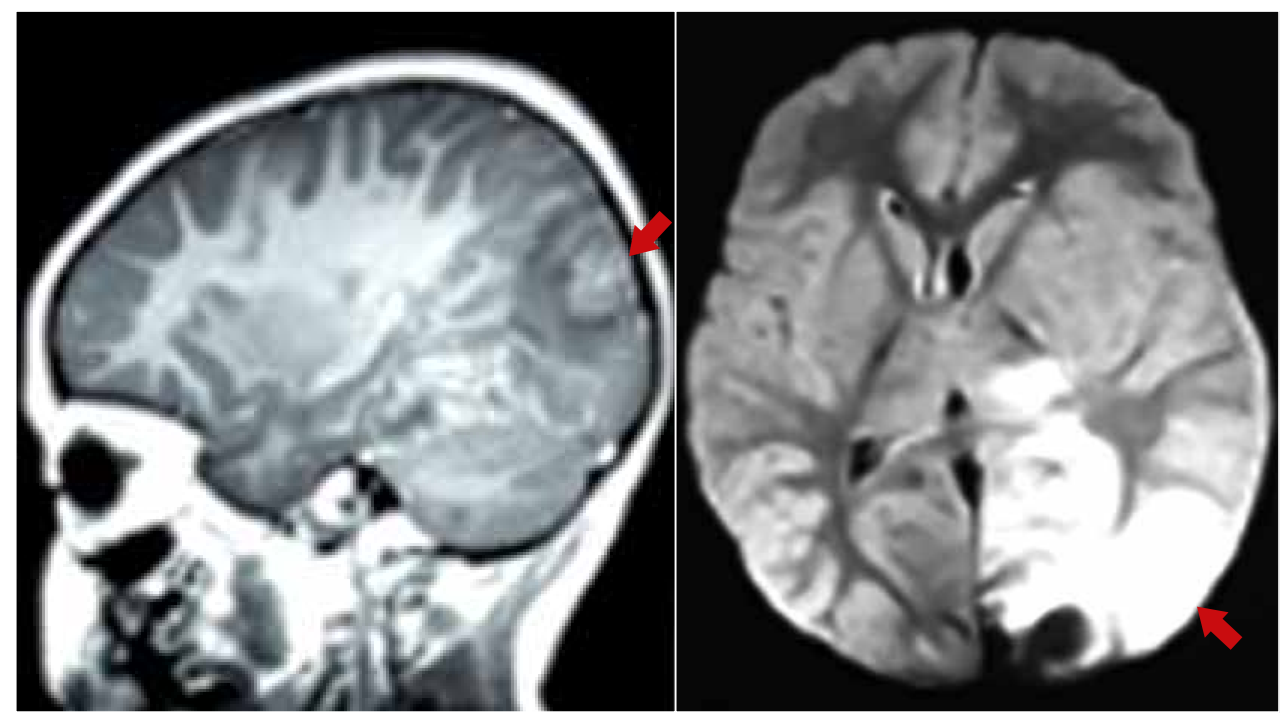

Figura 2. Resonancia magnética cerebral. En corte sagital ponderada en T1 sin contraste, se muestra foco de hiperseñal compatible con hemorragia subaguda asociado a hiposeñal de parénquima adyacente relacionable con proceso inflamatorio subyacente. Difusión (DWI) en axial muestra extensa restricción en lóbulo temporal izquierdo con imagen anterior nodular hipointensa en relación con sangrado descrito.

driguez-Sainz et al., describe HIC como debut en 35\% de los casos mientras el 65\% inició a partir de la segunda semana ${ }^{(12)}$. Takeuchi et al. realizó una revisión de once casos, cuatro presentaron hemorragia al momento del ingreso mientras que el resto entre el quinto al décimo quinto día ${ }^{(16)}$ reafirmando que la presentación temprana de HIC es poco frecuente.

Lamentablemente la evolución del paciente fue tórpida, con múltiples complicaciones y desenlace fatal. Algunos estudios estiman un $3 \%$ de mortalidad por encefalitis en pacientes pediátricos ${ }^{(17)} \mathrm{y}$ en caso de HIC hasta un $5,2 \%^{(12)}$. Respecto a la edad como factor de riesgo, Ward et al., refiere que los menores de un año tienen mayor riesgo de secuelas neurológicas ${ }^{(8)}$. Asimismo, los predictores de mortalidad son falla respiratoria, sepsis, neumonía, intubación y retraso del inicio de tratamiento antiviral ${ }^{(2,17)}$; los cuales se dieron en el presente caso. Por otra parte, Gnann JW et al., encontró que las convulsiones, déficits neurológicos focales y extensión o localización de la lesión cerebral no influyen en el pronóstico ${ }^{(2)}$.

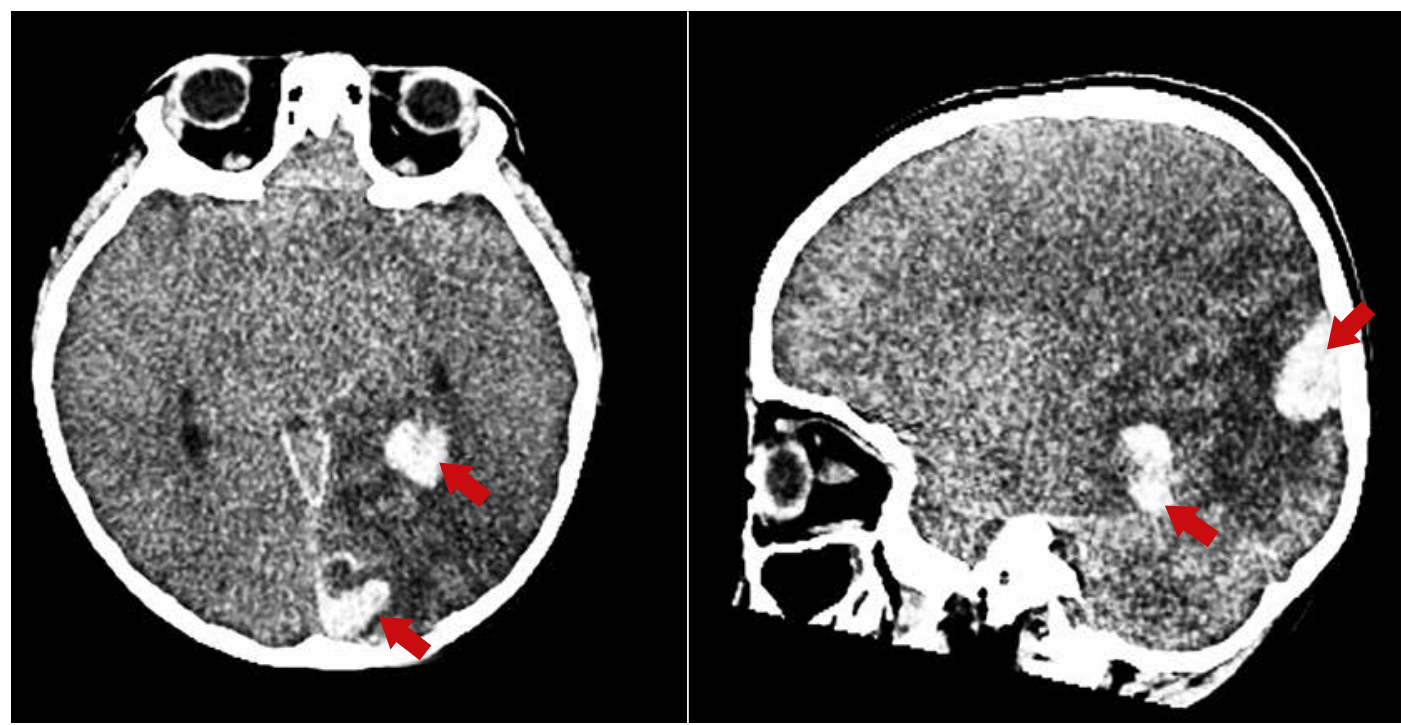

Figura 3. Tomografía cerebral con contraste. Corte axial y sagital. Se aprecia colección hemorrágica de $12 \mathrm{~mm}$ en región parieto-occipital izquierda que compromete el hipocampo izquierdo y otra de 26 x $12 \mathrm{~mm}$ adyacente a la línea media interhemisférica en la región occipital izquierda (córtex estriada), las que se asocian a edema vasogénico circundante y desplazando la línea media interhemisférica hacia la derecha. 
Como limitaciones del reporte debemos reconocer que no se realizó estudio de LCR ni de imágenes al ingreso, lo cual pudo haber modificado el curso de la enfermedad. Por ende, ante un cuadro clínico de encefalitis aguda y HIC, debemos sospechar de HSV, confirmar el diagnóstico e instaurar tratamiento oportuno, ya que el retraso está asociado a un peor pronóstico.

Con este reporte pretendemos contribuir al conocimiento acerca de la encefalitis por HSV, recalcando la presen-

\section{REFERENCIAS BIBLIOGRÁFICAS}

1. Bewersdorf JP, Koedel U, Patzig M, Dimitriadis K, Paerschke G, Pfister H-W, et al. Challenges in HSV encephalitis: normocellular CSF, unremarkable CCT, and atypical MRI findings. Infection. Infection. 2019;47(2):267-273. doi: 10.1007/s15010-018-1257-7

2. Gnann JW, Whitley RJ. Herpes Simplex Encephalitis: an Update. Current Infectious Disease Reports [Internet]. marzo de 2017 [citado 26 de enero de 2019];19(3). Disponible en: http://link.springer. com/10.1007/s11908-017-0568-7

3. Katyal N, Taqui AM, Tepper D, Beary JM, Newey CR. Fulminant herpes simplex virus type i encephalitis despite maximal medical therapy. Cureus 10(4): e2467. doi 10.7759/cureus.2467

4. Steiner I, Benninger F. Manifestations of Herpes Virus Infections in the Nervous System. Neurol Clin. 2018;36(4):725-738. doi: 10.1016/j. ncl.2018.06.005

5. De Tiège X, Rozenberg F, Héron B. The spectrum of herpes simplex encephalitis in children. Eur J Paediatr Neurol. 2008;12(2):72-81.

6. To TM, Soldatos A, Sheriff H, Schmid DS, Espinosa N, Cosentino G, et al. Insights into Pediatric Herpes Simplex Encephalitis From a Cohort of 21 Children From the California Encephalitis Project, 1998-2011. Pediatr Infect Dis J. 2014;33(12):1287-8. doi: 10.1097/INF.0000000000000422.

7. Tyler K. Update on herpes simplex encephalitis. Rev Neurol Dis. 2004 Fall;1(4):169-78.

8. Ward KN, Ohrling A, Bryant NJ, Bowley JS, Ross EM, Verity CM. Herpes simplex serious neurological disease in young children: incidence and long-term outcome. Arch Dis Child. 2012;97(2):162-5. doi: 10.1136/adc.2010.204677

9. Argyriou AA, Tsota I, Solomou E, Marangos M, Kalogeropoulou C, Petsas $\mathrm{T}$, et al. Intracerebral haemorrhage as a rare complication of tación atípica de la HIC con debut temprano y afectación extratemporal.

Agradecimientos: Al Dr. Carlos Ugas Charcape, por su apoyo en la interpretación de imágenes y al Dr. Carlos Llenque Fernández por la revisión crítica del artículo.

Fuentes de financiamiento: Autofinanciado.

Conflicto de intereses: $\mathrm{El}$ autor declara no tener conflicto de interés.

HSV-1 meningoencephalitis: Case report and review of the literature. Scand J Infect Dis. 2006;38(1):63-6.

10. Montano SM, Mori N, Nelson CA, Ton TGN, Celis V, Ticona E, et al. Herpes simplex virus encephalitis in Peru: a multicentre prospective study. Epidemiol Infect. 2016;144(8):1673-8. doi: 10.1017/S0950268815003222.

11. Wasay M, Mekan SF, Khelaeni B, Saeed Z, Hassan A, Cheema Z, et al. Extra temporal involvement in herpes simplex encephalitis. Eur J Neurol. 2005;12(6):475-9.

12. Rodríguez-Sainz A, Escalza-Cortina I, Guio-Carrión L, Matute-Nieves A, Gómez-Beldarrain M, Carbayo-Lozano G, et al. Intracerebral hematoma complicating herpes simplex encephalitis. Clin Neurol Neurosurg. 2013;115(10):2041-5. doi: 10.1016/j.clineuro.2013.06.016

13. Tonomura Y, Kataoka H, Yata N, Kawahara M, Okuchi K, Ueno S. A successfully treated case of herpes simplex encephalitis complicated by subarachnoid bleeding: a case report. J Med Case Rep. 2010;22;4:310. doi: 10.1186/17521947-4-310

14. Harada $Y$, Hara Y. Herpes simplex encephalitis complicated by cerebral hemorrhage during acyclovir therapy. Intern Med. 2017;56(2):225-229. doi: 10.2169/internalmedicine. 56.7386

15. Lo WB, Wilcock DJ, Carey M, Albanese E. Herpes encephalitis complicated by cerebral haemorrhage. J Neurol Neurosurg Psychiatry. 2013;84(12):1404-6. doi: 10.1136/jnnp-2013-305552

16. Takeuchi $S$, Takasato Y. Herpes simplex virus encephalitis complicated by intracerebral hematoma. Neurol India. 2011;59(4):594-6. doi: 10.4103/0028-3886.84344

17. Messacar K, Fischer M, Dominguez SR, Tyler KL, Abzug MJ. Encephalitis in US children. Infect Dis Clin North Am. 2018;32(1):145-162. doi: 10.1016/j.idc.2017.10.007 